\title{
Agriculture and human values
}

\author{
Harvey S. James Jr.
}

Published online: 24 April 2012

(C) Springer Science+Business Media B.V. 2012

Next year marks the 30th anniversary of Agriculture and Human Values. According to Google Scholar, there have been more than 1,000 articles published in the journal between 1984 and 2011. The most cited paper is currently Laura Raynolds' 2000 article "Re-embedding global agriculture: The international organic and fair trade movements."

Interest in the journal, as evidenced by submissions, continues to increase. Last year there were nearly 230 new papers submitted, representing an increase of more than $20 \%$ over the previous year. By comparison, the increase in submissions in 2010 over 2009 was $5 \%$. I publish approximately 40 papers a year, which means that the acceptance rate is below $20 \%$, and declining. Scholars who have papers accepted for publication should feel pleased with the increasing selectivity of the journal, but because of constraints in the number of papers I can accept, I worry that I am turning away good papers.

My publication backlog is under 1 year. This means that authors who have a paper accepted can now expect to see the paper in print within the next three or four issues. Accepted papers are published online within a few months of being accepted.

More than 300 reviewers provided reports on papers submitted last year. I am always grateful for the work of our anonymous reviewers. Theirs is an important and necessary scholarly service. I wish promotion and tenure committees gave more weight to their efforts.

The assistant editors associated with this journal provide an invaluable service in preparing accepted manuscripts for publication. I have had many authors express appreciation

H. S. James Jr. $(\bowtie)$

Department of Agricultural and Applied Economics, University of Missouri, 146 Mumford Hall, Columbia, MO 65211, USA

e-mail: hjames@missouri.edu for the careful editing work provided by Jeffrey Cole, Nancy Grudens-Schuck and Jessica Goldberger, who have served or are currently serving as assistant editors since I came on board as editor-in-chief in 2007. Not many peer reviewed journals provide the detailed editing that our editors do. The papers published here are better because of it. Many thanks to these competent scholars.

Finally, I acknowledge the work of our editorial board. If you, the reader, have not yet done so, then take a look at the inside front cover of this journal and review the names of those who help guide its direction and progress. There are outstanding scholars who serve on the editorial board. They provide feedback about issues relating to the development of the journal, make recommendations of reviewers, and often review papers themselves. I appreciate their service and note that I consider it quite an honor to be associated with them. It is because we have such a strong editorial board that the journal is a success.

This issue of Agriculture and Human Values contains three research articles and a special symposium on food sovereignty. In the first research article, Ferrell examines how agricultural activity defines gender roles and why such a link can impede transitions in agricultural production practices. Lillywhite, Simonson, and Wilson report results from a survey of US practitioners of alternative medicines in order to assess both the preferences for Chinese medicinal herbs and the long-term viability of a developing agricultural niche market. Magnan presents case studies of innovative farming structures that combine size and private investor characteristics with family ownership. The symposium, which is guest edited by Molly Anderson and Anne Bellows, contains an introduction by the editors and six research papers. Book reviews and the current listing of books available for review complete this issue of Agriculture and Human Values. 


\section{Editor's note}

We published a review by Amy Snively-Martinez of Maria Fonte and Apostolos Papadopoulos's edited book, Naming Food After Places, in the previous issue of Agriculture and
Human Values. In that review we listed the publisher as Ashford when it should have stated Ashgate Publishing Limited. We regret the error. 